\title{
MERCANTILIZAÇÃO E FINANCIAMENTO DO ENSINO SUPERIOR NO BRASIL/CEARÁ: DESVELANDO CONTRADIÇÕES ECONÔMICAS E SOCIAIS
}

\section{MERCHANTABILITY AND HIGHER EDUCATION FUNDING IN BRAZIL/ CEARA: UNVEILING CONTRADICTIONS ECONOMIC AND SOCIAL}

\author{
Paulo Henrique de Freitas Maciel $^{1}$ \\ Roberto Kennedy Gomes Franco ${ }^{2}$ \\ Tânia Serra Azul Machado Bezerra ${ }^{3}$
}

\section{RESUMO}

Este texto apresenta análise sobre a mercantilização e o financiamento do ensino superior, como vem ocorrendo no Brasil e, em particular no estado do Ceará, enfatizamos suas contradições fenomênicas e pontuamos aspectos da histórica dualidade educacional brasileira. A tessitura da investigação insere-se nos (des)caminhos do financiamento do ensino superior entre o público e o privado, vislumbrando programas como o FIES e o PROUNI. Metodologicamente pautados no materialismo histórico e dialético, confrontamos a oferta e financiamento do ensino superior privado no Brasil/Ceará com a expansão e sua relação com o mercado. Desenvolvemos uma pesquisa bibliográfica e documental com delimitação temporal dos dados publicados nos anos de 2013 a 2016, fornecidos pelo IBGE e os resultados das avaliações externas da educação superior no Brasil e no Ceará, realizados pelo MEC, em parceria com o INEP (Sinaes, Enade).

PALAVRAS-CHAVE: Ensino Superior - Mercantilização - Financiamento.

\begin{abstract}
ABSTACT
This paper presents analysis of the commercialization and financing of higher education, as has been happening in Brazil and in particular in the state of Ceará, we emphasize its phenomenal contradictions and we pointed out historical aspects of Brazilian educational duality. The tessitura of research is part of the (in) financing of higher education paths between the public and the private, seeing programs such as FIES and PROUNI. Methodologically guided by the historical and dialectical materialism, we confront the supply


and financing of private higher education in Brazil / Ceará with the expansion and its relationship with the market. We developed a bibliographical and documentary research with temporal delimitation of the data published in the years 2013 to 2016, provided by IBGE and the results of external evaluations of higher education in Brazil and Ceará, made by MEC in partnership with the INEP (Sinaes, Enade ).

KEYWORDS: Higher Education - Commodification - Financing.

\section{INTRODUÇÃO}

A educação, num sentido amplo, surge do intercâmbio entre os indivíduos, ao se debruçarem sobre a produção material de sua existência, que, a partir do trabalho coletivo proporciona cada vez mais conhecimento sobre o desconhecido, formalizando-se nas diversas dimensões da cultura. Ela é o próprio ato da existência do ser humano na terra. "Voltando-nos para o processo de surgimento do homem vamos constatar seu início no momento em que determinado ser natural se destaca da natureza e é obrigado, para existir, a produzir sua própria vida." (SAVIANI, 2006, p.154).

E assim a humanidade vai organizando a produção da sua existência material a partir do trabalho, na interação direta com a natureza, inclusive considerando o próprio ser humano como pertencente a esta natureza. Neste sentido, ela é “[...] é um fenômeno social e universal, sendo uma atividade humana necessária ao funcionamento de todas as sociedades [...]. Não há sociedade sem prática educativa e nem prática educativa sem sociedade.” (LIBÂNEO, 1994, p. 16-17).

A educação brasileira, em grande extensão, amarra significativos laços com o mercado extrator de mais-valia. Seguindo, pois, o paradigma da contemporaneidade, está aliada aos interesses dominantes, correspondendo ao ideal de formação para o trabalho alienado. Lembramos aqui que esse processo, dentro de uma razão capitalista, não se direciona para a emancipação e a realização humana. Pelo contrário, ao passo que produz riquezas para os donos do capital, segundo (MARX, 2004), traz miséria e estranhamento para os atores sociais. Tal perspectiva nos remete a um instigante ponto suscitado por (MÉSZÁROS, 2005, pg. 47): 
Será o conhecimento o elemento necessário para transformar em realidade o ideal da emancipação humana, em conjunto com uma firme determinação e dedicação dos indivíduos para alcançar, de maneira bem-sucedida, auto-emancipação da humanidade, apesar de todas as adversidades?

Estamos, assim, diante de complexa temática, por esta conciliar aspectos formativos, políticos, ideológicos, laborais e sociais. A articulação de tais categorias suscita a aproximação com um universo formativo que se distancia do modelo educacional capitalista. Revela-se, assim, as limitações das instituições formais de ensino diante da possibilidade de transformação/reflexão pela educação aliada a emancipação humana.

Considerando a íntima relação entre trabalho, educação e interação humana, evidenciase que essa não resulta de uma produção individual, mas coletiva, portanto, pertence à sociedade. Não sendo, portanto, justo que seja apropriada para outros fins que não a formação integral do ser humano. No entanto, na sociedade capitalista, o ensino, assim como quase tudo que é produzido pelo ser humano é passível de ser transformado em mercadoria.

Mas, qual a consequência de um produto do trabalho ser transformado em mercadoria? Antes de mais nada é necessário definir o que vem a ser mercadoria. A mercadoria possui dois elementos principais: o valor de uso, que é a qualidade de satisfazer uma necessidade humana, característica própria dos produtos e serviços, (como a roupa que nos veste ou a educação que nos proporciona uma imensidade de conhecimentos); e tais coisas ao mesmo tempo, possuem a qualidade de ser trocável, em determinadas proporções, por outra mercadoria, ou seja, o valor de troca. É este segundo elemento o que interessa ao capitalista quando decide empreender um negócio. A mercadoria representa o elemento principal da riqueza na forma capitalista de produzir. Conforme salienta (MARX, 1989, p. 210),

O produto, de propriedade do capitalista, é um valor-de-uso, fios, calçados etc. Mas, embora calçados sejam úteis à marcha da sociedade e nosso capitalista seja um decidido progressista, não fabrica sapatos por paixão aos sapatos. Na produção de mercadorias, nosso capitalista não é movido por puro amor aos valores-de-uso. Produz valores-de-uso apenas por serem e enquanto forem substrato material, detentores de valores-de-troca.

A consequência mais dramática de tudo ser transformado em mercadoria é que nas relações sociais predomina o valor-de-troca destas, tornando-se mais importantes e urgentes que a vida das pessoas, que com o suor de seu trabalho produzem estas riquezas materiais. "Uma relação social definida, estabelecida entre homens, assume a forma fantasmagórica de 
uma relação entre coisas" (MARX, 1989, p.81). As coisas (o capital) dominam as relações humanas. E quando isto ocorre com a educação, quando ela é mercantilizada, o aprendizado torna-se algo puramente quantitativo, como por exemplo, que o capitalismo formalizou por meio da teoria do Capital Humano.

Para debatermos sobre a mercantilização e o financiamento do ensino superior, lócus de nossa investigação, como vem ocorrendo no Brasil e, em particular no estado do Ceará, enfatizamos suas contradições fenomênicas e pontuamos aspectos da histórica dualidade educacional brasileira ${ }^{4}$. Partimos da constatação de que esta modalidade de ensino foi apropriada pelo empresariado como uma mercadoria, na qual este investe, munido do discurso da empregabilidade e da ascensão social via educação, movidos tão somente pela obtenção do lucro.

Com esta conotação, tal mercadoria - o ensino superior - assume predominantemente, valor de troca em detrimento de sua dimensão de utilidade tão enfatizada em discursos e documentos oficiais, a exemplo da Constituição Federal que em seu Art. 205 afirma: "A educação, direito de todos e dever do Estado e da família, será promovida e incentivada com a colaboração da sociedade, visando ao pleno desenvolvimento da pessoa, seu preparo para o exercício da cidadania e sua qualificação para o trabalho.” (BRASIL, 1988, p. 5). Ao analisarmos o fenômeno em pauta através de uma concepção dialética da educação, com suporte em suas contradições, percebemos que:

(...) a contradição não é considerada como "ilógica", paradoxal, mas como o verdadeiro motor do pensamento, ao mesmo tempo que é o motor da história, já que a história não é senão o pensamento que se realiza. $O$ pensamento não é mais estático, mas procede por contradições superadas, da tese (afirmação) à antítese (negação) daí à síntese (conciliação). (GADOTTI, 2003, p. 18).

É nesse movimento entre afirmação e negação de princípios/intenções que situamos o ensino superior no Brasil e o aprofundamento de sua mercantilização através de financiamento estatal. Mesmo oficialmente assegurado/promovido pelo Estado para fins de desenvolvimento pleno dos indivíduos, os recursos públicos destinados ao ensino superior tornam-se montante de enriquecimento privado. Em nossa compreensão os dividendos dos cofres públicos deveriam ser destinados às instituições públicas de ensino, aumentando assim o número de vagas ofertadas, investindo na formação e salários de professores, melhorando estrutura: bibliotecas, laboratórios, salas de aula, recursos didáticos etc.

Para realizar tal investigação, assumimos o pressuposto de que o processo de análise 
da realidade não pode ficar na superfície do problema em pauta. "A investigação tem de apoderar-se da matéria, em seus pormenores, de analisar suas diferentes formas de desenvolvimento, e de perquirir a conexão íntima que há entre elas. Só depois (...) é que se pode descrever, adequadamente, o movimento real.” (MARX, 1989, p. 16).

Neste sentido,

(...) o método é o conjunto das atividades sistemáticas e racionais que, com maior segurança e economia, permite alcançar o objeto - conhecimentos válidos e verdadeiros -, traçando o caminho a ser seguido, detectando erros e auxiliando as decisões do cientista. (LAKATOS E MARCONI, 2006, p.83).

Conforme as supracitadas autoras, a construção metodológica corresponde aos métodos e técnicas escolhidos pelo pesquisador, de forma que possam auxiliar o seu caminho no processo de investigação. Assim, é importante realçar que a pesquisa não é um instrumento pronto e acabado, constante, pois pode ser alterada diante das especificidades que irão existir no decorrer de sua realização.

Foi com esta compreensão de pesquisa que esta investigação buscou desvelar as contradições existentes na oferta do ensino superior privado no Brasil/Ceará. Não se trata, porém, de uma análise e exposição neutras, em que o autor se distancia do objeto estudado. Pelo contrário, sob a perspectiva metodológica do materialismo histórico e dialético, a investigação se estruturou de modo que possamos confrontar, dialeticamente, a teoria e a pesquisa documental e nossas interpretações e hipóteses acerca das relações sociais que foram estabelecidas neste campo que ao mesmo tempo em que é educativo é também financeiro.

Partimos, portanto, de uma realidade concreta: a oferta do ensino superior privado no Brasil/Ceará, considerando a expansão e sua relação com o mercado. Diante do objetivo desta proposta investigativa, tivemos como principal fonte de informações para análises os documentos estatísticos como os fornecidos anualmente pelo IBGE e os resultados das avaliações externas da educação superior no Brasil e no Ceará, realizados pelo MEC, em parceria com o INEP (Sinaes, Enade). Assim, apresentamos uma pesquisa documental que teve como delimitação temporal os dados publicados nos anos de 2013 a 2016. 


\section{EDUCAÇÃO ENTRE A EMANCIPAÇÃO E A MERCANTILIZAÇÃO}

Braverman (1974) nos ajuda a compreender a mercantilização da educação superior a partir da realidade norte americana da década de 1970, tempo histórico em que eram implementadas as políticas keynesianas ${ }^{5}$, quando aquele país, centro do desenvolvimento do capital, coloca a educação como um elemento fundamental para a acumulação capitalista e também como forma de garantir a própria existência deste sistema produtivo, seja na manutenção da ordem, ou no consumo.

A educação em geral atende a interesses que estão além da formação humana, pois enquanto mercadoria, a educação proporciona valorização e acumulação de capital. Esta é um meio e não um fim nesta sociedade do consumo e do lucro. “(...) um esboço do período recente basta para mostrar que muitas causas, a maioria das quais sem qualquer relação imediata com as exigências educacionais da estrutura do trabalho, estiveram em ação." (BRAVERMAN, 1974, p. 370).

São nefastas as consequências da mercantilização do ensino superior para a construção de uma sociedade emancipada. O Estado, ao não participar ativamente na construção de uma educação pública, com a qualidade necessária, contribui para a coisificação das relações sociais, reforçando ainda mais a dimensão do valor de troca em detrimento da qualidade. Da forma como são apropriados para/por um mercado que produz relações estranhadas, esses cursos envoltos sobre o viés da empregabilidade e do empreendedorismo, afastam-se significativamente, da construção de uma educação emancipadora.

Mencionados cursos formam profissionais que atuarão no mercado. Mas qual a relação entre estes profissionais e as ocupações laborais que terão pós cursos. Analisando a partir da constatação de (BRAVERMAM, 1974), para o qual a oferta educacional dos EUA atendia a objetivos que estavam além da educação enquanto processo de formação, ou seja, era um processo que movimentava dinheiro (capital) no mercado, e que, portanto, atendia a interesses do capital: lucros para os empresários da mercadoria educação.

Importa constatar que, ao longo do decurso civilizatório, a classe que se apoderou dos meios de produção e que, em consequência disso, se apropriou do trabalho alheio/do outro, tornando estranho o produtor e ciente de seu ofício opressor, não admite uma formação voltada à politicidade para a classe oprimida e transvalora a eticidade, no sentido freireano. Uma educação fundada na consciência do inacabemento poderia pôr em risco sua estabilidade como grupo dominante. Por esse, entre outros motivos, a educação ao longo dos tempos no 
Ocidente apresentou-se como poderoso agravante das desigualdades sociais e distanciou-se de contribuir para a emancipação humana.

A raiz mais profunda da politicidade da educação se acha na educabilidade mesma do ser humano, que se funda na sua natureza inacabada e da qual se tornou consciente. Inacabado e consciente de seu inacabamento, histórico, necessariamente o ser humano se faria um ser ético, um ser de opção, de decisão. Um ser ligado a interesses e em relação aos quais tanto pode manter-se fiel a eticidade quanto pode transgredi-la. (FREIRE, 1996, p. 110).

Com base numa experiência política para além de relações opressoras, foram incontáveis as revoltas dos grupos oprimidos que incansavelmente tentaram se libertar. Mesmo tendo pouco acesso a uma formação reflexiva, a precária existência os estimulava à luta. São exatamente esses momentos que (PAULO FREIRE, 1987) considera como práxis libertadora, na qual o indivíduo/coletivo toma consciência de sua realidade baseado nas experiências diárias e, assim, deparando-se com a exploração, procura libertar-se. Essa busca configura um ato educativo e formador da consciência de classe.

Nas relações mercantis, no entanto, o homem tem, até nossos dias, como é possível observar na mercantilização do ensino superior no Ceará/Brasil, composto sua história, perdendo valores humanos em troca de valores materiais, enaltecendo o "ter" em detrimento do "ser". Ao distanciar-se de seus aspectos de criticidade, o indivíduo perde a noção de seu papel histórico de transformação da realidade e se deixa coisificar, perdendo a oportunidade de redescobrir-se e, assim, recriar seu contexto social. Temos o que (FREIRE, 1987) considera de "distorção na história", em que a vocação humana do ser mais foi, ao longo do estabelecimento da sociabilidade dos homens, surrupiada pela violenta sede do opressor de acumular riquezas e poder.

É que, para eles, pessoa humana são apenas eles. Os outros, estes são 'coisas'. Para eles, há um só direito - o seu direito de viverem em paz, ante o direito de sobreviverem, que talvez nem sequer reconheçam, mas somente admitam aos oprimidos. E isto ainda, porque, afinal, é preciso que os oprimidos existam, para que eles existam e sejam generosos. (FREIRE, 1987, p. 45).

Freire (1987), nesta citação, traça com eficácia o perfil da classe dominante capitalista, ao mostrar que ela está, indiscutivelmente, comprometida com a manutenção da realidade de desumanização vivenciada pela sociedade contemporânea. No escopo de nossa compreensão histórica, com arrimo na leitura do primeiro volume do Capital (MARX, 1989), em 
observação de algumas formas de organização social vivenciadas pelo Ocidente, percebemos que, no decorrer dessas transformações, as formas de exploração foram se aperfeiçoando de acordo com o avanço tecnológico e a consequente expansão das forças produtivas. Assim sendo, é notório que o "ato desumanizador" foi viabilizado socialmente, no entanto, é imprescindível destacar que esse quadro depreciativo pode se reverter.

Em acordo com a lógica freireana, a referida reversão torna-se possível no momento em que o oprimido busca se afirmar como sujeito de decisão, questionando as injustiças impostas pelo opressor e, dessa forma, lutando radicalmente pela transformação concreta da sua realidade. Essa mudança deve basear-se na formulação histórica do "ato humanizador", mostrando a dialeticidade e a incompletude das relações sociais. Uma vez consciente de que a situação opressora é circunstancial, o indivíduo pode lutar para transformá-la, podendo promover a emancipação humana.

O legado histórico de tentativa de ruptura com uma educação comprometida com a exploração do homem pelo homem, no intuito de garantir valores humanos, proporcionando a implementação de uma sociedade concretamente justa e humanizada ainda está posta, no Brasil, no horizonte das possibilidades. É baseando-se nesta realidade até aqui apresentada que nesta pesquisa nos lançamos a analisar as contradições econômicas e sociais na oferta e financiamento do ensino superior nas instituições privadas, considerando a histórica dualidade da educação, no Estado do Ceará. Como também, assumindo a posição de questionar a sustentação da esfera privada com recursos públicos, em detrimento da precarização e pauperização do ensino superior público.

\section{3 (DES)CAMINHOS DO FINANCIAMENTO DO ENSINO SUPERIOR NO CEARÁ/BRASIL}

Segundo dados do Instituto Brasileiro de Geografia e Estatística (IBGE), em sua Síntese de indicadores sociais- Uma análise das condições de vida da população brasileira 2013, para o Brasil a porcentagem de pessoas frequentando instituições de ensino superior divide-se da seguinte forma entre os públicos e particulares de ensino: enquanto 24,2\% pertencem à rede pública, 75,8\% estão nas particulares. No Nordeste, a atuação da rede pública é de $35,3 \%$ e a particular responde por $64,7 \%$. Em nossa análise do fenômeno, o financiamento público de vagas nas redes particulares de ensino superior tem estimulado a 
expansão das instituições privadas, aliadas a implementação de políticas neoliberais. A este respeito (CHAVES, 2010, p. 02), argumenta:

\begin{abstract}
A política de expansão do ensino superior brasileiro é parte da reforma do Estado implementada no país, a partir da década de 1990, chegando aos dias atuais. A centralidade dessa reforma consiste na redefinição do papel do Estado que reafirma, por um lado, o valor do Estado democrático e republicano como o âmbito natural da justiça e como instância estratégica de redistribuição de recursos, ao mesmo tempo em que ele é desmantelado, em função do reforço darwiniano do mercado, procurando, a qualquer custo, a manutenção dos lucros.
\end{abstract}

Nesta perspectiva para o Estado do Ceará os dados são bastante próximos da realidade brasileira: pública 31,6\% e particular é 68,4\%. A despeito da atuação da iniciativa privada no ensino superior, temos que, para o grupo de 25 a 29 anos de idade, em 2012, observa-se que somente $11,2 \%$ estudavam, sendo que $8,8 \%$ do total cursavam ensino superior, mestrado ou doutorado. (IBGE, 2013). Mas, quais os significados de tamanha inserção da iniciativa privada no ensino superior? Tal atuação pode-se afirmar como sinônimo de democratização? Quais as consequências para o mercado de trabalho e para a sociedade como um todo?

Em nossa compreensão do fenômeno, a expansão do ensino superior privado incide no empresariamento do ensino e sua nefasta lógica de tratar os graduandos como clientes. Assim, quanto maior o poder aquisitivo dos sujeitos melhor o produto a ser consumido. Mesmo dentro da esfera privada, no Ceará, temos diferentes tipos de instituições de ensino superior pagas: umas com infraestrutura bem elaboradas e outras que funcionam precariamente e mais se parecem com um "intensivo de terceiro grau”. Estas últimas, com mensalidades a baixo custo, são destinadas aos que possuem menos condições de consumo, não possuem bibliotecas, laboratórios, grupos de pesquisa e/ou extensão e estão organizadas para ofertar um produto (formação) de baixíssima qualidade.

Cabe ressaltar que das mais elaboradas até as menos estruturadas, a maior fonte de recursos vem do financiamento público, basta visitarmos os sites das instituições ou do próprio MEC e observarmos que tal elemento, inclusive, é utilizado como atrativo aos novos clientes.

Os cartazes observados no portal oficial do FIES - Fundo de Financiamento ao Estudante do Ensino Superior, demonstram um pouco daquilo que debatemos até aqui: o processo de mercantilização do ensino superior através de financiamento público. Temos, nessa contextura, a educação como mais uma lucrativa mercadoria (expressão maior do capitalismo). Este é um fato evidenciado com o empresariamento do ensino, pois os 
empresários passam a perceber que podem vender cursos e mais cursos financiados com recursos públicos que lhes garantem proteção diante de possíveis inadimplências e fazendo crer que estes constituem um requisito básico para a garantia de emprego.

$\mathrm{Na}$ verdade, atualmente, o desemprego é consequência de mais uma crise estrutural do capital, que, entre outros aspectos, ocasiona a implementação de uma empresa que corta drasticamente funcionários para reduzir custos. No interior desse preceito, mesmo atingindo elevado índice de qualificação/profissionalização, grande parte dos indivíduos continua enfrentando a difícil empregabilidade (KOBER, 2004) e enfrentando um profundo mal-estar social e econômico.

Dessa forma, as mudanças na esfera educacional devem estar aliadas as transformações na maneira de organizar a vida material. Enquanto isso, contudo, percebe-se que a oferta e o financiamento público do ensino superior no Brasil, por exemplo, mantém vínculo direto com as relações econômicas determinantes da atual fase de reprodução do capital, responsável pelo cenário de crise. As transformações ocorridas nas últimas décadas, paradoxalmente, posicionam a educação como um "elevador" para a ascensão social. Como acentua Kober,

Poucas ideias têm hoje a força consensual daquela que vincula educação, emprego e desenvolvimento. A saber, o investimento em educação geraria retornos, em termos de produtividade para as empresas, de consequente desenvolvimento econômico e bem-estar social para o país e de aumento de renda e possibilidade de inserção social para o indivíduo. (2004, p.7).

Frente a referido cenário, apesar de todo um alarido em torno dos avanços recentes em relação à educação, ainda temos pouco a comemorar, pois a taxa de analfabetos acima de 15 anos, para o ano de 2014, se mantém em 8,3\%, conforme dados do IBGE de 2013, sendo que em 2002 eram de 11,9\%. De acordo com esse mesmo instituto, relativo também ao ano de 2014, a taxa de escolarização das crianças entre 0 a 3 anos era de 24,6\%; e 4 a 5 anos, 82,7\%, sendo que o Plano Nacional de Educação de 2002 a 2010 tinha como meta universalizar o atendimento escolar a essas faixas etárias até 2016. A proporção de jovens entre 15 e 17 anos que frequenta o ensino médio é de 84,2\% em 2012, em 2010 era de 81,5\%.

Sobre o ensino superior, o dado marcante é a oferta privada de ensino ser mais que três vezes maior do que a oferta pública, como elucida os dados do IBGE. Ou seja, a educação superior amplia-se sem dúvida, mas, seguindo a lógica de mera mercadoria. Nesta lógica oferta-se somente aquilo que proporcione lucro, sejam sapatos, ensino ou armas para as 
guerras que existem atualmente no mundo. Pouco ou nada interessa ofertar algo que servirá para o bem da humanidade, ou para o desenvolvimento da autonomia na atuação social e na empregabilidade.

\section{CONSIDERAÇÕES FINAIS}

A mercantilização do ensino superior, com o predomínio do setor privado sobre o público, traz para esse setor os princípios do capitalismo, a partir dos quais a competição entre indivíduos é interpretada como a forma de toda a sociedade se beneficiar, segundo o liberalismo clássico. Com o desenvolvimento do capitalismo esta tese não tem mais validade e ficou claro que a competição traz benefícios apenas para uma camada, cada vez menor da sociedade. Desta feita, "para o mercado não há sociedade, há indivíduos em competição. E para o mundo da acumulação flexível, não há lugar para todos, só para os considerados mais competentes, os que passam pelo metro que mede o tempo fugaz da mercadoria e de sua realização”. (FRIGOTTO, 2011, p. 251).

Para uma compreensão do processo de expansão da oferta de ensino superior em curso, a partir da análise da sociedade em que vivemos, a sociedade do capital, da mercadoria, importa contextualizar essa expansão e suas consequências para classe trabalhadora. "Não é possível, portanto, compreender radicalmente a história da sociedade contemporânea e, consequentemente, a história da educação, sem se compreender o movimento do capital" (SAVIANI, 2005, p.17).

Nesse sentido, a ideia que predomina nesta mercantilização é a de capital humano. De acordo com Frigotto (2005, p.40), a ideia do capital humano remete ao pós Segunda Guerra Mundial e baseia-se na crença de que a educação torna as pessoas produtivas. Esta teoria foi formalizada pelo Prêmio Nobel de economia, Schultz, que analisou a rápida recuperação da Alemanha e do Japão, comparando a situação desses países à do Reino Unido, onde ainda havia racionamento de alimentos muito tempo depois da guerra. $\mathrm{O}$ autor concluiu que a velocidade de recuperação decorreria de uma população saudável e altamente educada. Segundo ele, a educação torna as pessoas produtivas e a boa atenção à saúde aumenta o retorno do investimento em educação.

Assim, introduziu a compreensão de "capital educacional", relacionando-o especificamente aos investimentos em educação, desprezando, para tanto, e não era de se 
esperar o contrário, o fato de capital não se resumir a uma dimensão quantitativa. Além do mais, no caso específico do trabalhador, diferentemente de uma máquina, não é possível quantificar com tanta precisão o quanto cada pessoa carrega consigo de capital humano.

A teoria de capital humano explicaria o diferencial no desenvolvimento das nações e, também, das oportunidades de trabalho dos indivíduos. "Nesta perspectiva, a contribuição da educação é de melhorar a capacidade de os indivíduos utilizarem os recursos disponíveis para produzir bens e serviços; solucionar a problemática da desigualdade econômica e promover a mobilidade social e o combate à pobreza." (SOUSA, 2005, p.101). Em outras palavras, de acordo com este pensamento, aqueles que não obtêm êxito econômico e educacional assim se encontram por falta de competência e de interesse individual, pois a liberdade de concorrer no mercado propicia "igualdade de oportunidade" a todos. (Ressaltemos as aspas entre igualdade de oportunidades).

A existência desse mercado da educação funciona como forma de internalizar no indivíduo a responsabilidade pela competição e a própria condição social no mercado como se fosse algo natural. Como salienta Mészáros (2008, p.44):

Em outras palavras, no sentido verdadeiro amplo do termo educação, trata-se de uma questão de "internalização" pelos indivíduos (...) da legitimidade da posição que lhes foi atribuída na hierarquia social, juntamente com suas expectativas "adequadas" e as formas de conduta "certas", mais ou menos explicitamente estipuladas nesse terreno.

Além do elemento ideológico de manutenção de seres humanos passivos, ao mobilizar recursos monetários, o setor educacional funciona como um fator que proporciona ao capital a sua valorização. Assim, a construção de prédios, equipamentos, força de trabalho funcionam como um elemento de demanda, no qual a sociedade capitalista se move. Aqui não interessa formar pessoa que desenvolvam seus conhecimentos para contribuir com a sociedade, mas formar contingentes populacionais, que pagarão por isso, ou seja, simplesmente "formar" pessoas que, muito provavelmente, nunca trabalharão na sua área.

$\mathrm{Na}$ dinâmica capitalista, na qual o desemprego é um fator de equilíbrio desta sociedade, a educação cumpre uma função além da formação de espírito. Fruto da sua própria contradição, o capitalismo funciona com desemprego, ou seja, de antemão sabemos que parcelas da população ficarão de fora do mundo do trabalho pela dinâmica do capital. Como observa Braverman (1974, p.326), a relação entre emprego e desemprego é bem próxima. 
Desse modo, a massa de emprego não pode ser separada de sua correlata massa de desemprego. Nas condições do capitalismo, o desemprego não é uma aberração, mas parte necessária do mecanismo de trabalho do modo capitalista de produção. É continuamente produzido e absorvido pela energia do próprio processo de acumulação. (...) Essa população excedente relativa, o exército de reserva industrial, assume forma variada na sociedade moderna, inclusive os desempregados; os temporariamente empregados; (...) os exércitos de imigrantes, tanto agrícolas como fabris; a população negra com suas taxas extraordinariamente elevadas de desemprego; e as reservas estrangeiras de trabalho. (grifos nossos)

Saviani (2005) também colabora com esta discussão quando nos esclarece que, educação formal para todos no sistema de produção capitalista esta longe de significar garantia de emprego.

O acesso a diferentes graus de escolaridade amplia as condições de empregabilidade do indivíduo o que, entretanto, não lhe garante emprego, pelo simples fato de que, na forma atual do desenvolvimento capitalista, não há emprego para todos: a economia pode crescer convivendo com altas taxas de desemprego e com grandes contingentes populacionais excluídos do processo. É o crescimento excludente, em lugar do desenvolvimento inclusivo que se buscava atingir no período keynesiano. (2005, p. 21).

Nem mesmo este acesso aos níveis educacionais, como destaca Saviani (2005), foi conquistado no Brasil. Para o ensino superior evidenciamos dois programas governamentais que explicitam a opção mercantil do governo ao tratar a educação: o PROUNI (O Programa Universidade para Todos) e o FIES. O PROUNI por suas características insere-se nesta dinâmica de saída do setor público da educação e ao mesmo tempo de incentivo por parte deste para a expansão da iniciativa privada, por meio da compra de vagas nas instituições privadas através, por exemplo, das isenções tributárias.

Outro programa criado foi o FIES, programa de financiamento estudantil criado pelo Ministério da Educação (MEC), que possibilita aos estudantes de instituições privadas de ensino superior o financiamento de curso superior em até $100 \%$, com um juros de 3,4\% ao ano incidentes sobre o financiamento. Depois da conclusão do curso, o estudante terá 18 meses para pagar o empréstimo.

Com base nestes dois programas, é que apresentamos análises sobre o estado da educação no ensino superior, entre o público e o privado, com um olhar para o estado do Ceará, evidenciando as contradições sociais desse tipo de programa e as possibilidades que se 
apresentam para a classe trabalhadora neste processo contínuo de lutas pelos seus direitos fundamentais.

\section{REFERÊNCIAS}

ANDERSON, Perry. Balanço Neoliberal. In SADER, Emir; GENTILI, Pablo (organizadores) - Pós-neoliberalismo: as políticas sociais e o Estado democrático. Vários autores. Rio de Janeiro: Paz e Terra, 1995.

BRASIL. Constituição (1988). Constituição da República Federativa do Brasil. Brasília, DF: Senado, 1988.

BRAVERMAN, H. Trabalho e capital monopolista. Rio de Janeiro: Zahar, 1974.

CHAVES, Vera Lúcia Jacob. Expansão da Privatização/Mercantilização do Ensino Superior Brasileiro: a formação dos oligopólios. Educação \& Sociedade (Impresso), v. 31, p. $481-500,2010$.

FREIRE, Paulo. Pedagogia do Oprimido. Rio de Janeiro: Paz e Terra, 1987.

FREIRE, Paulo. Pedagogia da Autonomia: saberes necessários à prática educativa. São Paulo: Paz e Terra, 1996 (Coleção Leitura).

FRIGOTTO, Gaudêncio. Os circuitos da história e o balanço da educação no Brasil na primeira década do século XXI. Revista Brasileira de Educação, v. 16, n. 46, jan./abr. 2011. Disponível em <http://www.cedes.unicamp.br> Acesso em 24 de janeiro de 2013.

Concepções e mudanças no mundo do trabalho e o ensino médio. In:

CIAVATTA, Maria; RAMOS, Marise. (Orgs.) Ensino médio integrado: Concepções e contradições. São Paulo: Cortez, 2005. 
GADOTTI, Moacir. Concepção Dialética da Educação: um estudo introdutório. São Paulo: Cortez, 2003.

IBGE. Instituto Brasileiro de Geografia e Estatística. Síntese de indicadores sociais-Uma análise das condições de vida da população brasileira. 2013. Disponível em <http://www.ibge.gov.br/home/estatistica/populacao/condicaodevida/indicadoresminimos/sint eseindicsociais2013/SIS_2013.pdf> Acesso em 18 de janeiro de 2014.

KOBER, Claudia Mattos. Qualificação Profissional - Uma Tarefa de Sísifo. Campinas SP: Autores Associados, 2004 (Coleção Educação Contemporânea).

LAKATOS, Eva Maria; MARCONI, Marina de Andrade. Fundamentos de Metodologia Científica. 6. ed. São Paulo: Atlas, 2006.

LIBÂNEO, José Carlos. Didática. São Paulo: Cortez, 1994. (Coleção Magistério $2^{\circ}$ Grau/ Série Formação de Professor).

MARX, Karl . Manuscritos Econômico-filosóficos. Tradução de Jesus Ranieri, São Paulo: Boitempo: 2004.

K. O Capital: crítica da economia política. Vol. I, Livro I - O processo de produção do Capital. 13. ed. Rio de Janeiro: Bertraud do Brasil, 1989.

MÉSZÁROS, István. A Educação Para Além do Capital. 2. ed. São Paulo: Boitempo, 2008. István. A Educação Para Além do Capital. Tradução de Isa Tavares. São Paulo: Boitempo, 2005.

SAVIANI, D. Transformações do capitalismo, do mundo do trabalho e da educação. In: LOMBARDI, J.C.; SAVIANI, D.; SANFELICE, J.L. (Org.). Capitalismo, trabalho e educação. 3. ed. Campinas: Autores Associados; Histedbr, 2006. 
Trabalho e educação: fundamentos ontológicos e históricos: Revista Brasileira de Educação v. 12 n. 34 jan./abr. 2005.

SOUSA, Antonia de Abreu. As recomendações do banco mundial para a educação profissional e o vigor da teoria do capital humano no contexto do neoliberalismo. In. OLIVEIRA, Elenilce Gomes; (Orgs.). Educação Profissional: análise contextualizada. Fortaleza: CEFET-CE, 2005. (Coleção Atualidades em Educação).

\footnotetext{
${ }^{1}$ Mestre em Educação Brasileira/UFC. Graduado em Economia/UFC. Economista/UFCA(Universidade Federal do Cariri).

${ }^{2}$ Doutor em Educação Brasileira/UFC. Professor Adjunto UNILAB (Universidade da Integração Internacional da Lusofonia Afro-Brasileira. E-mail: robertokennedy@unilab.edu.br.

${ }^{3}$ Doutora em Educação Brasileira/UFC. Professora Adjunta da Universidade Estadual do Ceará. E-mail institucional: tania.azul@uece.br.

${ }^{4}$ Consideramos dualismo educacional a dimensão classista que assola a escola brasileira, separando, de forma abismal, as escolas frequentadas por filhos das classes menos favorecidas, das escolas frequentadas pelos economicamente mais abastados. (SAVIANI, 2006).

${ }^{5}$ Considerado momento de "ouro" do capitalismo em virtude da expansão dos lucros vivenciada na fase do segundo pós-guerra. (ANDERSON, 1995, p. 10).
}

RECEBIDO EM: Setembro de 2016

APROVADO EM: Outubro de 2016 